\title{
FERTILIZATION CAPACITY OF ROOSTER SPERMATOZOA UPON THE BIOCHEMICAL CHANGES OF SEMEN
}

(Received: 11. 12. 2012)

\author{
By \\ E. A. El-Gendy, M. M. Ahmed*, Sh. M. El-Tantawy and Sh. A. Ibrahim* \\ Department of Animal Production, Faculty of Agriculture, Cairo University, Giza - Egypt. \\ *Department of Animal Production, National Research Center, Dokki, Giza - Egypt.
}

\begin{abstract}
An experiment was carried out to study the effects of biochemical changes in rooster semen on the fertilization capacity of the spermatozoa. Chickens of two lines (CE2 and CE4) were used. Seven treatments of semen were designed and included the incubation of sperm with a bacterial plasmid (pUK18), a mixture of the plasmid and lipofectin at 5 or $2.5 \%$ concentration and the incubation of spermatozoa with lipofectin and a semen extender (BPSE). The progenies were obtained from the insemination of hens by the semen of different treatments. Sperm motility was greatly influenced by the treatments. Motility was significantly the highest in the control semen and averaged $92.42 \%$ and highly significantly declined to the renege of 52.08 and $58.75 \%$ in the semen samples treated with the plasmid, lipofectin at 2.5 or $5 \%$ concentration and diluted with BPSE. The percentage of live sperm was not affected by the addition of the plasmid. The addition of the plasmid and lipofectin or the dilutent BPSE resulted in a significant reduction in the percentage of live sperms. The percentage of live sperms ranged 59-62\% when the plasmid, lipofectin and BPSE were all together added to the semen samples. The percentages of dead and abnormally-shaped sperm reached 26.88 and $17.13 \%$ respectively, in the semen treated with plasmid, lipofectin 5\% and BPSE. Fertility averaged $88.22 \%$ in the eggs of hens inseminated with the control semen, and significantly decreased to $42.14 \%$ when semen was incubated with the plasmid pUC18, and reached $58.98 \%$ when semen was treated with plasmid, lipofectin (5\%) and BPSE.
\end{abstract}

Key words: bacterial plasmid, lipofectin, rooster spermatozoa, semen dilution.

\section{INTRODUCTION}

Semen characteristics can be affected by age of the rooster, lighting schedule, season, body weight, and diet (Sexton, 1986 \& 1987), as well as the changes in the biochemical composition of the semen (El-Gendy et al., 2007). The characteristics include the concentration, motility, viability and morphology of spermatozoa. Many of these parameters correlate with the fertilizing capacity of the spermatozoa.

Fowl spermatozoa show similar patterns of motility regulation with more than $60 \%$ of spermatozoa motile at $30^{\circ} \mathrm{C}$ and virtually no spermatozoa motile at $40^{\circ} \mathrm{C}$ (Wishart and Wilson, 1999). Florescent strains have successfully been used to determine live and dead sperm ratios (Lake and Stewart, 1978; Bilgili and Renden, 1984; and Bayyari et al., 1990).

Fowl semen is low in volume, but is highly concentrated with spermatozoa. Therefore, the dilution of semen is common to increase its volume and to increase the number of hens that can be inseminated. The proper dilution uniformly distributes spermatozoa, so that the proper dosage can be delivered during insemination. It also sustains and protects spermatozoa during short or long term storage. Semen dilution is based on the biochemical composition of chicken semen. Because glutamic acid is the most prominent anionic constituent of avian seminal plasma, so it is considered a standard component of most of the diluents (Lake and McIndoe, 1959). Sexton (1977) developed a phosphate buffered semen diluent known as Beltsville Poultry Semen Extender (BPSE). This diluent was successfully used to assess the insemination dose required for optimum fertility following short-term storage. Fertility value of more than $88 \%$ was reported for white leghorn hens weekly inseminated with 20 million spermatozoa suspended in BPSE.

Fertility levels of more than $90 \%$ were achieved when a dose of 100 million sperm cells suspended in BPSE was used. It was reported that a dilution rate of 1:4 and a weekly insemination 
dose of 20 million sperms was determined to be the maximum extension rate of chicken semen diluted in the BPSE. The function of the extender BPSE as a storage medium was assessed by Sexton and Fewlass (1978), using various diluent components for fowl semen stored at $5^{\circ} \mathrm{C}$. Spermatozoa maintained the capability of fertilization in diluents with osmolarities ranging 250-460 mosM/kg $\mathrm{H}_{2} \mathrm{O}$. In hypo-osmotic conditions, spermatozoa displayed increased incidence of bent necks. This defect was frequently found in diluted chicken and turkey semen, and was negatively correlated with fertility (Bajpai and Brown, 1964; and Clark et al., 1984). Giesen and sexton (1982) observed a disappearance of turkey spermatozoa over an 18hour storage period, suggesting that spermatozoa swell and burst in vitro. It was hypothesized that hypertonic diluents could improve sperm survival in vitro (El-Gendy et al., 2007).
(1987) and Sato et al. (2003) indicated that lipofectin stabilizes exogenous DNA and keeps it intact. The fertility of cock spermatozoa was detracted when treated with lipofectin (Rottmann et al., 1992; Squires and Drake, 1993). However, Trefil et al. (1996) observed continuous egg fertility for three weeks of hens inseminated with lipofectin-treated spermatozoa.

Because of their natural role in insemination, that spermatozoa are interestingly able to seek out the female pronucleous with such precision seems reasonable enough to think that they may be utilized to deliver exotic DNA to the target ovum and also at the same time resulting in the successful integration into the genome of the introduced gene (Khoo et al., 1992; and Yin et al., 2009).

The objective of this study was to evaluate the fertilization capacity of cock sperms under different conditions of dilution, loading with lipofectin and bacterial plasmid.

Table (1): The chemical composition of the Beltsville poultry semen extender (BPSE)

\begin{tabular}{lc}
\hline \multicolumn{1}{c}{ Constituent } & grams/liter \\
\hline Potassium diphosphaate. $3 \mathrm{H}_{2} \mathrm{O}$ & 12.70 \\
Sodium glutamate & 8.67 \\
Fructose (anhydrous) & 5.00 \\
Sodium acetate. $3 \mathrm{H}_{2} \mathrm{O}$ & 4.30 \\
$\mathrm{TES}^{1}$ & 1.95 \\
Potassium citrate & 0.64 \\
Potassium monophosphate & 0.65 \\
Magnesium chloride & 0.34 \\
& \\
$\mathrm{~d} \mathrm{H}_{2} \mathrm{O}$, was added to the mixture to reach $1000 \mathrm{ml}$ & \\
\hline $\mathrm{pH}$ & 7.50 \\
Osmotic pressure (m.Osm./kg. $\left.\mathrm{H}_{2} \mathrm{O}\right)$ & 333 \\
\hline ', N-tris (Hydroxymethyl) methyl-2aminoethane sulfonic acid
\end{tabular}

Light microscopic autoradiograms showed that radioactive DNA was associated with a number of sperm cells but not all the sperm cells were labeled indicating that some sperm cells were unable to pick up DNA. Evidence from electron microscope examination of the autoradigraphs obtained after in situ hybridization showed that foreign DNA was present within the sperm nucleus. This clearly showed that DNA had been internalised into the sperm head. The fluorescence in situ hybridization used by Nakanishi and Iritani (1993) showed that $51.6 \%$ of the exogenous DNA-lipofectin-treated sperm retained the exogenous DNA. Fellgner et al.

\section{MATERIALS AND METHODS \\ 2.1. Genetic background of the chickens}

Two lines of chickens (CE2 and CE4) were used in this experiment. Line CE2 is normally feathered and line CE4 is naked neck. Both lines have been originally derived from a heterozygous naked-neck local chicken population in Egypt (ElGendy, 2009). Both lines are being maintained in small randombred flocks for 10 generations.

\subsection{Experimental design}

Ten males and 20 females were randomly assigned in each line. Semen samples were individually collected from the males of each line 
and were immediately pooled to two samples, 5 males each. Seven different treatments were applied to the pooled semen samples. In treatment $1\left(\mathrm{~T}_{1}\right)$, semen was used as the control treatment. In treatment $2\left(\mathrm{~T}_{2}\right)$, semen was treated with the plasmid pUC18 (2.5 $\mu \mathrm{g} / 100 \mu \mathrm{l}$ semen), and then heat incubated. In treatments 3 and $4\left(\mathrm{~T}_{3}\right.$ and $\left.\mathrm{T}_{4}\right)$, semen was treated with a mixture of the plasmid pUC18 $(2.5 \mu \mathrm{g} / 100 \mu 1$ semen) and lipofectin (Life Technologies, Carlsbad, California, USA) at 5.0 $\mu \mathrm{l} / 100 \mu \mathrm{l}$ semen $\left(\mathrm{T}_{3}\right)$ or $2.5 \mu \mathrm{l} / 100 \mu \mathrm{l}$ semen $\left(\mathrm{T}_{4}\right)$, and then heat incubated. In treatments 5 and $6\left(\mathrm{~T}_{5}\right.$ and $\left.\mathrm{T}_{6}\right)$, semen was diluted $(1: 4, \mathrm{v}: \mathrm{v})$ with Beltsville poultry semen extender (BPSE, Table 1) proposed by Sexton (1977), treated with a mixture of the plasmid pUC18 $(2.5 \mu \mathrm{g} / 100 \mu \mathrm{l}$ semen) and lipofectin at $5.0 \mu \mathrm{l} / 100 \mu \mathrm{l}$ semen $\left(\mathrm{T}_{5}\right)$ or $2.5 \mu \mathrm{l} / 100 \mu \mathrm{l}$ semen $\left(\mathrm{T}_{6}\right)$, and then heat incubated. In treatment $7\left(\mathrm{~T}_{7}\right)$, semen was diluted with BPSE $(1: 4, \mathrm{v}: \mathrm{v})$, mixed with the plasmid pUC18 $(2.5 \mu \mathrm{g} / 100 \mu \mathrm{l}$ semen $)$, and then heat incubated. Heat incubation was by the exposure of semen to $37^{\circ} \mathrm{C}$ for 30 minutes using water bath. Each treatment was repeated three times, forming three replicates. For all treatments, hens of each line were inseminated with the treated semen. Four hatches were obtained. Eggs were collected for 10-15 days for each hatch and were incubated. Upon hatch, chicks were wing banded, by line and dam. All chicks per hatch were housed in floor chambers in a conventional open house with routine management.

\subsection{Sperm capacity}

Sperm capacity was assessed in all treatments by the estimation of:

2.3.1. Sperm concentration: Sperm concentration was determined, where the semen of the given treatment was diluted at a rate of 1:200 using a physiological saline solution $(1 \mathrm{ml} \mathrm{Nacl} \mathrm{3 \% ,2 \textrm {ml }}$ eosin $2 \%$, and $50 \mathrm{ml}$ deionized water). A drop of the diluted semen was put on a standard hemacytometer slide which is equally divided into 25 squares, each is also equally sub-divided into 16 cells, each cell is $1 / 20 \times 1 / 20 \times 1 / 10 \mathrm{~mm}^{3}$. Sperms were counted as the sum of sperm counts in five squares on the slide, the four squares at the corners and the square at the center. Sperm concentration was then calculated according to Sorensen (1979):

Sperm concentration $(\mathrm{sperm} / \mathrm{ml})=$ [counted sperm $\mathrm{x}$ dilution rate $\mathrm{x} 4000 \mathrm{x} 1000] \div(5 \times 16)$ The dilution rate was 200 , and the value of 4000 denotes to the product of the cell volume.

2.3.2. Sperm motility: Individual motility of the sperm was determined. A drop of the semen of each treatment was mixed with $200 \mu$ l of BPSE and warmed to $37^{\circ} \mathrm{C}$ under light microscope. The individual motility was subjectively and numerically estimated on a rank from zero for no individual motility to $100 \%$ for maximum individual motility (Morisson et al., 1997).

2.3.3. Sperm viability: The parameters of spermatozoa viability included percentages of live, dead and abnormally-shaped sperm. Forty microliters of semen samples of each treatment were added to $150 \mu \mathrm{l}$ of the staining solution (eosin $16 \mathrm{~g} / \mathrm{l}$ and nigrosin $60 \mathrm{~g} / \mathrm{l}$ in BPSE) and put onto slide. Two minutes later, smears were performed for each sample and spermatozoa were observed, using microscope with an oil immersion objective. Live spermatozoa were seen white in color because they were eosin- impermeable. However, dead spermatozoa were pink because they became eosin-permeable. Two hundred spermatozoa per sample were observed and the percentages of live, dead and abnormally-shaped spermatozoa were estimated (Sorensen, 1979).

2.3.4. Fertility and hatchability: Fertility and hatchability were calculated for each treatment and chicken line.

\subsubsection{Statistical analysis}

The data set of sperm characteristics was subjected to the analysis of variance using the statistical analysis system (SAS, 1999). The sources of variances included effects of line, treatment, replication and the interaction between line and treatment. Line and treatment significance were assessed by least squares means.

\section{RESULTS AND DISCUSSION \\ 3.1. Sperm characteristics}

Table (2) presents the levels of significance of different effects on sperm capacity. The results indicate that semen characteristics were highly significantly influenced by treatment differences. Also, replication influenced only sperm viability measurements (percentages of live, dead and abnormally-shaped spermatozoa). Neither line differences nor line by treatment interaction influenced the sperm characteristics. These results reveal that sperm capacity influenced by the biochemical changes in semen composition. The effect of the genetic background on sperm characteristics was totally absent.

Semen characteristics under different treatments are shown in Table (3). Sperm concentration was significantly the highest $\left(4.1 * 10^{9} \mathrm{sperm} / \mathrm{ml}^{3}\right)$ in the control sample $\left(\mathrm{T}_{1}\right)$. The incubation of semen with the plasmid pUC18 $\left(\mathrm{T}_{2}\right)$ significantly reduced the sperm concentration 
Table (2): Levels of significance of different sources of effects on sperm capacity

\begin{tabular}{lcrrrrr}
\hline Source & Df & Concentration & \multicolumn{1}{c}{ Motility } & \multicolumn{1}{c}{ Live } & \multicolumn{1}{c}{ Dead } & \multicolumn{1}{c}{ Abnormal } \\
\hline Model & 15 & $<0.0001$ & $<0.0001$ & $<0.0001$ & $<0.0002$ & $<0.0001$ \\
Line (L) & 1 & 0.7735 & 0.3759 & 0.6862 & 0.1504 & 0.4703 \\
Treatment (T) & 6 & $<0.0001$ & $<0.0001$ & $<0.001$ & $<0.0001$ & $<0.0001$ \\
Replication & 2 & 0.2104 & 0.0566 & 0.0014 & 0.0106 & $<0.0001$ \\
L * T & 6 & 0.5278 & 0.7290 & 0.5183 & 0.4429 & 0.8753 \\
\hline
\end{tabular}

by $18.14 \%$. The incubation of semen with the plasmid in the presence of lipofectin $\left(\mathrm{T}_{3}\right.$ and $\left.\mathrm{T}_{4}\right)$ reduced the sperm concentration by about 26$42 \%$. Also, the dilution of semen with BPSE $\left(\mathrm{T}_{7}\right)$ resulted in a significant reduction in sperm concentration by $51.55 \%$, and was not significantly different from that in the semen samples treated with plasmid, lipofectin and BPSE $\left(\mathrm{T}_{5}\right.$ and $\left.\mathrm{T}_{6}\right)$. Therefore, it is obvious that sperm concentration was greatly changed when semen samples were subjected to different treatments. Hafez (1974) reported that fowl semen although is low in volume it is highly concentrated. A cock eject varies from 0.2 to $0.5 \mathrm{ml}$ and contains an average density of about $3 \times 10^{9} \mathrm{sperm} / \mathrm{ml}$.

Sperm motility was significantly the highest in the control semen $\left(T_{1}\right)$ and was not significantly changed when incubated with the plasmid $\left(\mathrm{T}_{2}\right)$. A dramatic and significant decline by 32.83 and $26.96 \%$ in sperm motility accompanied the treatment of semen with lipofectin at 5 and $2.5 \%$ concentrations, respectively $\left(\mathrm{T}_{3}\right.$ and $\left.\mathrm{T}_{4}\right)$. Motility significantly declined by $22.46 \%$ when semen was diluted with BPSE $\left(\mathrm{T}_{7}\right)$. The motility declined more when lipofectin was at $5 \%$ concentration than when was at $2.5 \%$ concentration, and with or without BPSE. This means that lipofectin primarily impedes the sperm motility, and this motility impedance positively correlated with lipofectin concentration. The depression in fowl spermatozoa motility in response to different environmental changes was also reported by Wishart and Wilson (1999), where more than 60\% of spermatozoa motile at $30^{\circ} \mathrm{C}$ and virtually no spermatozoa motile at $40^{\circ} \mathrm{C}$.

The percentage of live sperms was $84.83 \%$ in the control semen $\left(\mathrm{T}_{1}\right)$ and was not significantly affected by the incubation with the plasmid $\left(\mathrm{T}_{2}\right)$. The incubation of semen with the mixture of the plasmid and lipofectin $\left(\mathrm{T}_{3}\right.$ and $\left.\mathrm{T}_{4}\right)$ or the dilution of semen by BPSE $\left(\mathrm{T}_{7}\right)$, resulted in a significant reduction by $15.12-21.22 \%$ in the percentage of live sperms and the reduction was even more and reached 26.28 and $30.35 \%$ when the plasmid, lipofectin (5 or $2.5 \%$ concentration) and BPSE were all together incubated with the semen $\left(T_{5}\right.$ and $\mathrm{T}_{6}$ ). Accordingly, the percentage of dead sperms significantly increased in all treatments compared to that observed in the control treatment $(7.75 \%)$. The increase in percentage of dead sperms varied from about 2 -folds in the semen treated with the plasmid $\left(\mathrm{T}_{2}\right)$ to about 2.5 -folds in the semen treated with the plasmid, lipofectin at $2.5 \%$ concentration and BPSE $\left(\mathrm{T}_{6}\right)$. The treatment of semen with only BPSE $\left(T_{7}\right)$ resulted in increasing the percentage of dead sperms by about 1.5 -folds.

Similar to the increasing trend of the percentage of dead sperms due to the different treatments of semen, the percentage of abnormally-shaped sperms increased but with less magnitude. The abnormally-shaped sperms basically represented $7.42 \%$ in the control semen $\left(\mathrm{T}_{1}\right)$, and increased to as high as about 1.3 -folds in the semen treated with plasmid, lipofectin at $2.5 \%$ concentration and BPSE $\left(\mathrm{T}_{6}\right)$. It seems that the percentages of live, dead and abnormally-shaped spermatozoa were significantly influenced by the addition of the plasmid, lipofectin and BPSE to the semen; however the addition of plasmid only to the semen did not alter the percentages of live, dead and abnormally-shaped sperms. These results indicate that many sperms were damaged by the changes in semen biochemical composition, resulting in significant increases in the sperm mortality and misshaping. Morisson et al. (1997) reported significant differences in semen characteristics between two lines of Rhode Island Red chickens. The percentages of live, dead and abnormal spermatozoa were $92,3.6$, and $4.3 \%$ in one line versus $89,6.1$ and $5.2 \%$ in the other line.

\subsection{Fertility and hatchability}

Because the concentration, motility, viability and morphology of spermatozoa correlate with the fertilizing potential of the spermatozoa, so the fertility and hatchability were obtained for the collected eggs of each treatment and line (Table 4). Fertility was 90.72 and $85.71 \%$ in lines CE2 and CE4 respectively, with an average of $88.22 \%$ in the eggs of hens inseminated with control semen $\left(T_{1}\right)$. Fertility remarkably and significantly decreased in both lines among different treatments 
Table (3): Sperm Characteristics (LSM \pm SE), overall lines, under different semen treatments.

\begin{tabular}{|c|c|c|c|c|c|c|c|c|c|c|c|}
\hline \multirow{2}{*}{ Treatment } & \multirow{2}{*}{ No. } & \multicolumn{2}{|c|}{ Concentration } & \multicolumn{2}{|c|}{ Motility } & \multicolumn{2}{|l|}{ Live } & \multicolumn{2}{|l|}{ Dead } & \multicolumn{2}{|c|}{ Abnormally-shaped } \\
\hline & & $* 10^{9}$ & $\downarrow$ & $\%$ & $\downarrow$ & $\%$ & $\downarrow$ & $\%$ & $\uparrow$ & $\%$ & $\uparrow$ \\
\hline $\mathbf{T}_{1}$ & 12 & $4.19 \pm 0.26^{a}$ & & $92.42 \pm 3.00^{\mathrm{a}}$ & & $84.83 \pm 2.95^{a}$ & & $7.75 \pm 3.03^{c}$ & & $7.42 \pm 1.45^{d}$ & \\
\hline $\mathbf{T}_{2}$ & 12 & $3.43 \pm 0.26^{b}$ & 18.14 & $85.92 \pm 3.00^{a}$ & 7.03 & $80.88 \pm 2.95^{a}$ & 4.66 & $10.67 \pm 3.03^{b c}$ & 37.68 & $9.88 \pm 1.45^{c d}$ & 33.15 \\
\hline $\mathbf{T}_{3}$ & 12 & $3.08 \pm 0.26^{b c}$ & 26.49 & $62.08 \pm 3.00^{c}$ & 32.83 & $72.00 \pm 2.95^{b}$ & 15.12 & $18.87 \pm 3.03^{a b}$ & 143.48 & $8.00 \pm 1.45^{\mathrm{cd}}$ & 7.82 \\
\hline $\mathbf{T}_{4}$ & 12 & $2.41 \pm 0.26^{\mathrm{cd}}$ & 42.48 & $67.50 \pm 3.00^{b c}$ & 26.96 & $71.54 \pm 2.95^{b}$ & 15.67 & $21.13 \pm 3.03^{\mathrm{a}}$ & 172.65 & $9.29 \pm 1.45^{\mathrm{cd}}$ & 25.20 \\
\hline $\mathbf{T}_{5}$ & 12 & $2.55 \pm 0.26^{\mathrm{cd}}$ & 39.14 & $52.08 \pm 3.00^{d}$ & 43.65 & $62.54 \pm 2.95^{c}$ & 26.28 & $26.13 \pm 3.03^{\mathrm{a}}$ & 237.16 & $14.75 \pm 1.45^{a b}$ & 98.79 \\
\hline $\mathbf{T}_{6}$ & 12 & $2.31 \pm 0.26^{\mathrm{cd}}$ & 44.87 & $58.75 \pm 3.00^{d}$ & 36.43 & $59.08 \pm 2.95^{c}$ & 30.35 & $26.88 \pm 3.03^{a}$ & 246.84 & $17.13 \pm 1.45^{\mathrm{a}}$ & 130.86 \\
\hline $\mathbf{T}_{7}$ & 12 & $2.03 \pm 0.26^{d}$ & 51.55 & $71.66 \pm 3.00^{b}$ & 22.46 & $66.83 \pm 2.95^{b c}$ & 21.22 & $20.25 \pm 3.03^{a}$ & 161.29 & $11.83 \pm 1.45^{b c}$ & 59.43 \\
\hline
\end{tabular}

${ }^{\mathrm{a}-\mathrm{d}}$, LS means of same trait with different superscripts are significantly different $(\mathrm{P} \leq 0.05)$.

$\downarrow$ or $\uparrow$, indicates the percentage of reduction or increase in the sperm character due to different treatments, compared to the control treatment $\left(\mathrm{T}_{1}\right)$ $\mathrm{T}_{1}=$ non-treated semen (control semen). $\mathrm{T}_{2}=$ semen treated with the plasmid. $\mathrm{T}_{3}=$ semen treated with the plasmid and lipofectin 5\%.

$\mathrm{T}_{4}=$ semen treated with the plasmid and lipofectin 2.5\%. $\mathrm{T}_{5}=$ semen treated with the plasmid and lipofectin 5\% and BPSE

$\mathrm{T}_{6}=$ semen treated with the plasmid and lipofectin $2.5 \%$ and BPSE. $\mathrm{T}_{7}=$ semen treated with the plasmid and BPSE

Table (4): Effects of different semen treatments on fertility and hatchabilitys.

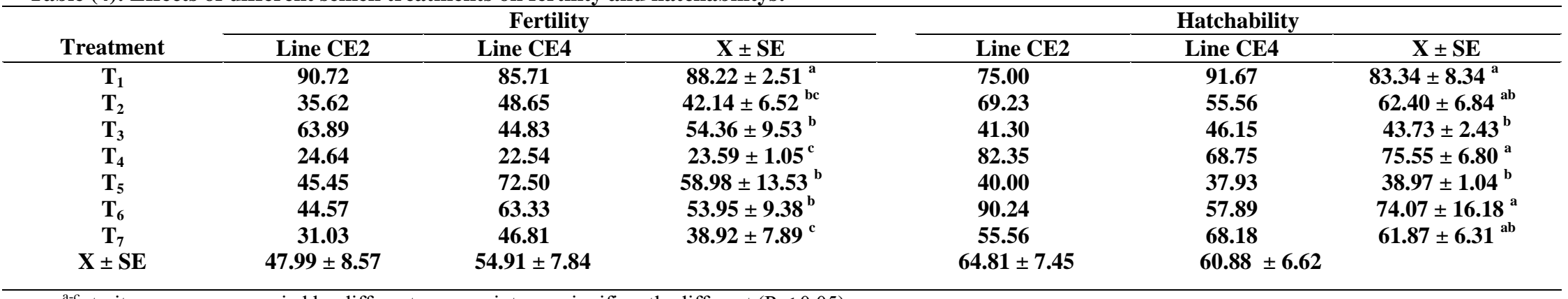

${ }^{\mathrm{a}-\mathrm{c}}$, trait means accompanied by different superscripts are significantly different $(\mathrm{P} \leq 0.05)$.

$\mathrm{T}_{1}=$ non-treated semen (control semen). $\mathrm{T}_{2}=$ semen treated with the plasmid. $\mathrm{T}_{3}=$ semen treated with the plasmid and lipofectin $5 \%$

$\mathrm{T}_{4}=$ semen treated with the plasmid and lipofectin $2.5 \%$. $\mathrm{T}_{5}=$ semen treated with the plasmid and lipofectin $5 \%$ and BPSE.

$\mathrm{T}_{6}=$ semen treated with the plasmid and lipofectin $2.5 \%$ and BPSE. $\mathrm{T}_{7}=$ semen treated with the plasmid and BPSE. 
of semen, with no obvious trend. The incubation of spermatozoa with the plasmid pUC18 $\left(\mathrm{T}_{2}\right)$ significantly decreased the average fertility to $42.14 \%$. Fertility was $23.59 \%$ when semen was incubated with the plasmid and lipofectin $2.5 \%$ $\left(\mathrm{T}_{4}\right)$, and reached $53.95 \%$ when semen was treated with plasmid, lipofectin $2.5 \%$ and BPSE $\left(\mathrm{T}_{6}\right)$. In three of four lipofectin treatments of semen, fertility was not reduced as much as the reduction in other semen treatments in which lipofectin was not used. No significant difference in fertility was obtained between both lines.

Hatchability averaged $83.34 \%$ in both lines for the eggs of hens inseminated with untreated control semen $\left(\mathrm{T}_{1}\right)$, and was significantly decreased to $62.40 \%$ upon the treatment of semen with the plasmid $\left(\mathrm{T}_{2}\right)$. The reduction in hatchability was obvious and reached 43.73 and $38.97 \%$ when the semen was treated with the plasmid and lipofectin 5\% $\left(\mathrm{T}_{3}\right)$, and the diluents BPSE as well $\left(\mathrm{T}_{5}\right)$. But the treatment of semen with the plasmid, lipofectin $2.5 \%$ without the diluents BPSE $\left(\mathrm{T}_{4}\right)$ and with the diluents BPSE $\left(\mathrm{T}_{6}\right)$ resulted in hatchability of 75.55 and $74.07 \%$, respectively. It might be of meaning that lipofectin in general sustained and protected the plasmid and also diminished the deleterious effect of incubation of semen with the plasmid on the fertilizing potential and hatching.

According to Rottmann et al. (1992) and Squires and Drake (1993), the fertility of cock spermatozoa was detracted when treated with lipofectin. Trefil et al. (1996) observed continuous egg fertility for three weeks of hens inseminated with lipofectin-treated spermatozoa, and the fertility reached $52.3 \%$ during the third week. The fluorescence in situ hybridization used by Nakanishi and Iritani (1993) showed that $51.6 \%$ of the exogenous DNA-lipofectin treated sperm retained the exogenous DNA. The fertility of eggs was $47 \%$ for the DNA incubated with sperm, $23 \%$ for the electroporated sperm and $67 \%$ for the lipofectin-treated sperm.

\section{REFERENCES}

Bajpai P.K. and Brown K.E. (1964). The effect of different temperatures on the metabolic activity, morphology, and fertilizing capacity of turkey semen. Poult. Sci., 43:1501 1508.

Bayyari G.R., Cook J.R., Harris G.C., Macy L.B., Slavik M.F., and Skeeles J.K. (1990). The evaluation of chicken spermatozoa using luorescent staining in a 96- well format. Poult. Sci., 69:1602-1605.
Bilgili S.F. and Renden J.A. (1984). Fluorometric determination of avian spermatozoa viability and concentration. Poult. Sci.63: 2275-2277.

Clark R.N., Bakst M.R. and Ottinger M.A. (1984). Morphological changes in chicken and turkey spermatozoa incubated under various conditions. Poult. Sci. 63:801-805.

El-Gendy E.A. (2009). A model for the genetic employment of chickens local to warm climate. 1. Crossing with a fast growing strain and growth patterns of the crossbreds. International Journal of Poultry Science, 8:299-306.

El-Gendy E. A., Gad A.Y. and Mostageer A. (2007). Sperm-mediated gene transfer in poultry 1 . The relationship with cock sperm viability. Arab. J. Biotech., 10 (1):1-12.

Fellgner P.L., Gadek T.R., Holm M., Roman R., Chan H.W., Wenz M. , Nortro J.P., Ringold G.M. and danielsen M. (1987). Lipofection: A highly efficient, lipid-mediated DNAtransfection procedure. Proc. Nati. Acad. Sci., USA, 84: 7413-7417.

Giesen A.F. and Sexton T. J. (1982). Boltsville Poultry Semen Extender:7.Comparison Of Commercial Diluents For Holding Turkey Semen Six Hour $15^{\circ} \mathrm{C}$.Poult. Sci., 62:379381.

Hafez E.S.E. (1974). Reproduction in Farm Animals $3^{\text {rd }}$ ed., LEA \& FEBIGER, Philadelphia, USA, pp. 312-317.

Khoo HW., Ang LH., Lim H.B. and Wong KY. (1992). Sperm cells as vectors for introducing foreign DNA into zebrafish. Aquaculture, 107:1-19.

Lake P.E. and McIndoe W.M. (1959). The glutamic acid and creatine content of cock seminal plasma. Biochem. J., 71:303-306.

Lake P.E. and Stewart J.M. (1978). Preservation of fowl semen in liquid nitrogen -an improved method. Poult. Sci., 19:187-194.

Morisson M., Bordas A., Petit J.M., JayatVignoles C., Julien R. and Minvielle F. (1997). Associated effects of divergent selection for residual feed consumption on reproduction, sperm characteristics, and mitochondria of spermatozoa. Poult. Sci.,76: 425-431.

Nakanishi A. and Iritani A. (1993). Gene transfer in the chicken by spermmediated methods. Mol. Reprod. Dev., 36:258-61.

Rottmann O.J., Antes R., Höfer P. and Maierhofer G. (1992). Liposomes mediated gene transfer 
